His general health was good, and his appetite improved, but he steadily lost weight. This continued for some time, his weight on Aug. 15th being but 2 st. He has always been a very difficult child to feed, and during the hot weather in August last he could hardly be induced to take any nourishment. Thinking that the treatment might have something to do with this, I discontinued giving the extract for a week, but this seemed only to make him weaker in body and extremely depressed in spirits. Since the weather became cooler he has improved; his appetite is better, and his weight is 2 st. $3 \frac{1}{2} \mathrm{lb}$. In his case the improvement was less remarkable than in the others. His condition, especially mentally, was not nearly so serious, and he has hardly yet begun to feel the bodily benefit, which appears late in the treatment, and which I shall notice below. He was passing in his urine in the second week of October 24 per cent. of urea. His height now is $35 \frac{1}{2}$ in., being a gain of $1 \frac{1}{2}$ in. in less than four months. This is no doubt due in part to the fact that his deformity has been treated by massage and suspension.

Remarks. - In reviewing these cases there are certain points that present themselves for consideration. In the first place, the absence of symptoms of discomfort due to the treatment, such as are usually noticed in myxcedema, must he obscrved. The doses given were quite equal to those given to adults, and beyond a very slight rise of temperatare no perceptible disoomfort was apparent. Bymptoms of improvement, however, did not occur so soon as in cases of myxœdema, no change of any importance being noted in the first week. It will be sten that in three of the cases there was a marked decrease in weight at first, this being accompanied by a decided decrease in bulk. After a time, however, the weight showed a progressive increase, due, apparently, to a deposit of adipose and other healthy tissues. Whether the decrease was accompanied by a marked excretion of mucin in the urine could, as I observed above, not be demonstrated; probably, however, this was so. With regard to the excretion of urea, in Cases 1 and 2 this was decidedly increased under the treatment. In Case $\overline{4}$ the percentage before treatment was largely above the normal, and subsequently diminished. I could find no explanation for this phenomenon. The rate of improvement seemed to have a detinite relation with the age at which the treatment was cornmenced, being most marked in the youngest (Case 3 ) and least marked in the oldest (Case 4). Cases 1 and 4 developed, under treatment, profuse sweating of the head, accompanied by a disagreeable odour, almost fæcal in character. It may be noted that three of the four cases were males. The engravings are from photographs.

Queen-street, Mayfair, $\mathbf{W}$.

\section{A CASE OF \\ SPORADIC CRETINISM IN AN INFANT; TREATMENT BY THYROID EXTRACT.}

\section{By A. GORDON PATERSON, M.A., M.D. EdiN.}

Is view of the great benefits derived by myxcedematous patients from treatment by thyroid extract, in whatever way administered, the following case of a sporadic cretin infant and the results obtained therein from the thyroid extract may be of interest as indicating a possible plan by means of which the condition of the unfortunate victims of the disease may be greatly ameliorated if not cured.

A male infant first came under my observation when eleven months old. The parents were healthy young people, being both sober and hard-working; there was no consanguinity between them. I could not discover, after most careful investigation, any trace of disease in either of the parents' families or in any of the collateral branches. The child was breast-fed till he was seven months old, when he was fed by the bottle. He was brought to me on account of obstinate constipation and non-closure of the fontanelles. At seven montts it was noticed that the bowels were very confined and that simple remedies had lost their effect. It was also thought that he was backward. At nineteen months his condition was practically the same, with the exception that he had grown a little. The general condition of the infant at eleven months of agc was as follows: There were no signs whatever of teething. He hacl never suffered from diarrhoea; he had not had convulsions or any febrile disease. His height and weight were not recorded, vut at nineteen months his height was 25 in.
The head was large and the anterior fontanelles were very open, the division of the frontal bone being easily felt. Tha occipito-parietal junctions were very open, and on the right side there was a triangular space devoid of bone; all ths sutures were very wide apart. The hair, which was brown in colour with a reddish tint here and there, was very scanty, fine, and short. The scalp was covered with branny scurf. The face was of a dirty yellow colour, with no blush on the cheeks or nose. The eyelids were reddish and the veins dis. tinct. He suffered from ciliary blepharitis occasionally. His nose was a short pug, and very broad and flat at ths root; the cheeks were thick and pale; the mouth was open; the tongue was very large and always protrud. ing; the ears were moderate in size, but waxy; the neck was thick and short. The sterno-thyroids were very distinct; ho thyroid gland could be felt, but there was a slight swelling over the right clavicle; there were no pseudo-lipomata. The abdomen was barrel-shaped and very tense, the veins being very distinct; it was, like the whole body of the child, very bluish and mottled. There was a smal umbilical hernia of the size of a hazel-nut. The limbs were hard, swollen, stumpy, and very cold and purplish. The mottling was most marked from the elbows to the finger tips, and similarly in the legs from the knees to the toes. The bands and feet were remarkably thict and swollen with firm cedema, and they were very cold: There was a slight anterior curvature of the tibin, otherwise no signs of rickets were present; there was no beading of the ribs. The spine wis kyphotic. Ther were no fatty growths or hairy growth between the scapulæ. The skin was always dry and harsh. There wers no moles, warts, nævi, eczema, or ichthyosis. The sęretior of sweat was almost entirely absent; saliva was abundant, but there was no nasal secretion. The muscular develop. ment was apparently absent, but this was due evidently to the thickening of the limbs, as shown by the resuits after treatment. The reflexes were normal as far as could be judged, but it was difficult to be certain. The skin sensibility was fair ; the sight and bearing were good. The lefo testicle was quite down, but the right was not yet in tive scrotum. The rectal temperature was $97 \cdot 2{ }^{\circ} \mathrm{F}$. The chi $d$ was extremely susceptible to cold and liked to be always placec near the fire. The voice was harsh and thick when crying for he could not say a word and hardly made a sound. As regards mental development, spontaneity was absolutel absent. There was no intelligence. The sleep was yariable. The child was very anæmic; the appetite was good; the bowels were very constipated and the motions pale; the live: and spleen were not enlarged ; the urine was a clear yellow the heart was normal, but the pulse was very feeble; the respiration was noisy, but regular; there were no enlarged lymph glands. The only differences noticeable between the condition at eleven months and nineteen months were as follows : The anterior fontanelle was still very open, but the left parieto-occipital was closed, and in the right a Wormian bone could be felt ; the sutures were closing up; the hair was more abundant; the redness and veins of the eyelids hac disappeared. The veins of the abdomen were mostly gone, and the mottling and tenseness were less; the umbilica hernia was smaller. The muscular power was improving, but he could not yet sit up and could only just move the limbs. The rectal temperature was $96^{\circ}$; in the groin it was $95.8^{\circ}$ The mental development was improving, as he could put out the hand and place the teat of the bottle in his mouth. He now recognised his father and mother, and occasionally smile? to them. He could drink only while lying down and from the bottle, as all the fluid escaped when he was sitting up, owing to the size of the tongue. These, briefly, were the chief points noticed when the thyroid treatment was begun. This consisted in the administration once daily of ten drops of the extract, plain

I will now shortly note his condition after five months thyroid treatment. After the third dose of the extract it was noticed that the face seemed to be smalker; the tongue was perceptibly more in the mouth, the hands were softer, and spontaneous action was greater, as was shown by his rubbing his eyes and grasping anything held towards him, which result was undoubtedly due to the softening of the arms allowing of motion. After the fourth dose he had a bad cold, and the extract was discontinued, but as symptoms of bron chitis threatened it was resumed, and, curiously, the next day the whole of the catarrhal and febrile symptoms dis appeared. After the sixth dose the tongue bad become, though still very large, quite flat, and was wholly within the mouth, and when he cried the cavity of the mouth and throat could easily be seen, which was an impossibility before, The 
next point is that the bowels had become quite regular and cood in appearance. The urine was not in any way affected. The most marked feature, with the exception of the diminution in the size of the tongue, was that the child had lost the cold feeling, and even when left alone in his crib no longer became cold-in fact, his bodily temperature was at this time laways nractically normal. At the end of a week his limbs had become quite soft and pliable, and he could even sit up in his perambulator with a little help. He noticed things a great deal, and his colour was nearly natural. At the end of month he began to show signs of teething and now at the end of five months he has eight teeth. He can sit up alone and crawl on the floor, is active, and tries to say a few words. When placed on his feet he makes attempts to walk. The contanelles are closed, except the anterior, which is still slightly open. Such, briefly, is the extraordinary improvement obtained by five months' thyroid treatment, where during the previous eight months the condition had remained in statu quo.

One further note in regard to the case. In December, 1892, the mother gave birth to a female child. The labour 'was easy, but it was a breech case. The child was born alive, but only lived for about twenty minutes. The placenta was very small, and the membranes were very tough and gelatinous. The weight of the child was $10 \mathrm{lb} .14 \mathrm{oz}$.

P.S.-At present (after eight months' treatment) the child ias sixteen teeth, can stand, and tries to walk. He also manages to say several words.

Ascot.

\section{A CASE OF}

\section{SPORADIC CRETINISM TREATED BY}

\section{FEEDING WITH THYROID EXTRACT.}

BY JOHN B. HELLIER, M.D LOND.

ECMURE ON DISEASES OF WOMEN AND CHILDREN AT YORKSHIRE COLLEGE, LEEDS. AND SURGEON TO THE HOSPITAL FOR TYMEN AND CHILDREN, LEEDS.

THE following case is published to show the benefit which may be obtained by feeding a cretinous child with thyroid extract. The patient first came under my care in February

FIG. 1.

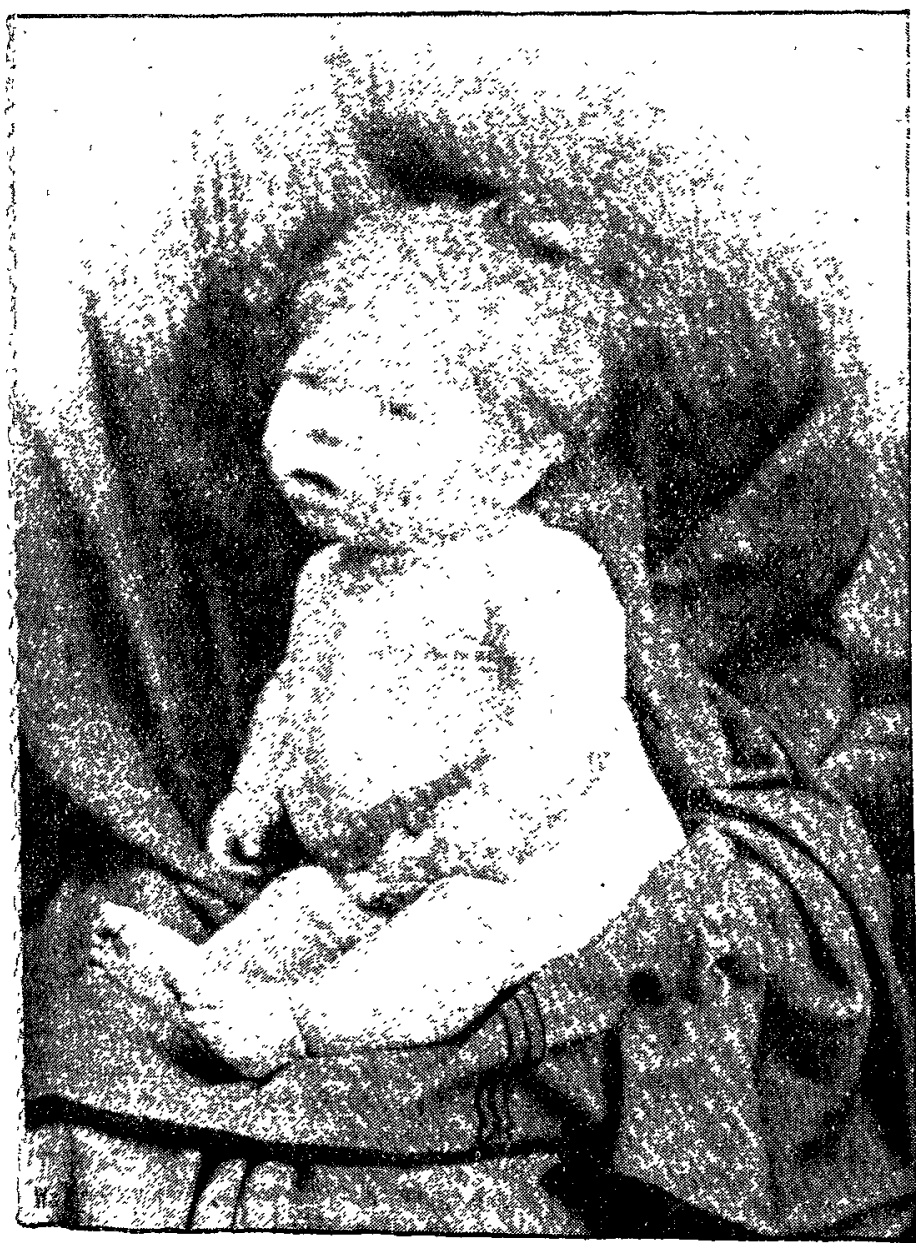

Birora tre it $2 \theta$ it:
1892. when she was two years and four months old. She then showed symptoms of rickets combined with sporadic cretinism. She had no teeth; the fontanelles were open; the ribs were beaded, the epiphyses swollen, and the tibiæe and fibulæ were curved. The eyelids and cheeks were swollen and puffy, the lips were prominent, and the tongue was too laroe. Subcutaneous myxodematous swellings, of harder or softer consistence, were found under the chin, over the posterior triangles of the neck, on each side of the lumbar spine, over the back of the upper arms on both sides, and over the origin of the flexor and extensor muscles of the wrists and hands. The hands were swollen, and the ball of the thumb on both sides was thickened by marked swelling. The legs and feet were also irregularly swollen, the swellings

FIG. 2.

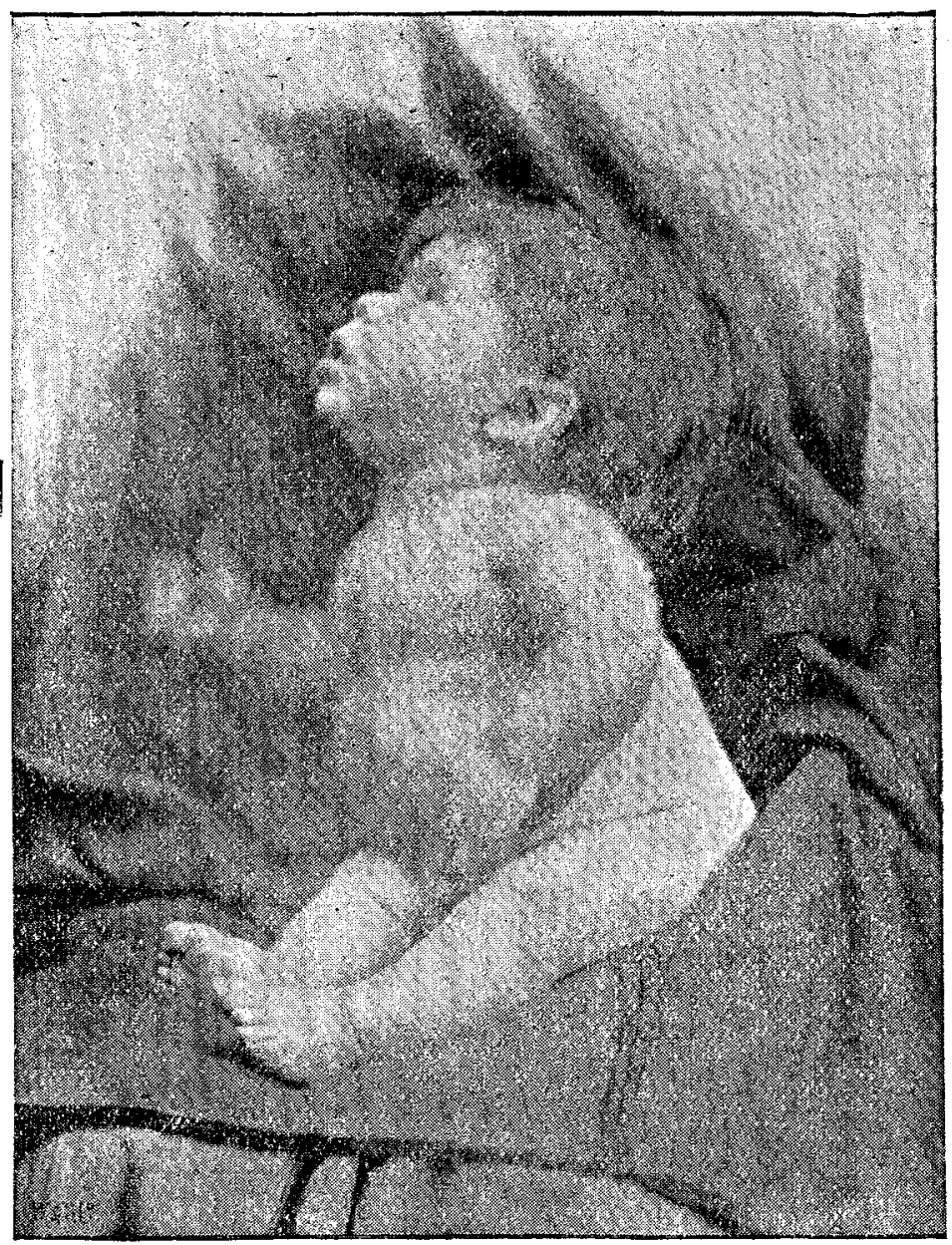

Before treatment.

being specially marked upon the front of the two thighs. There was no pitting anywhere. The child had umbilical herria and a greatly distended abdomen, but the liver and spleen were not enlarged. The skin was harsh and rough, the hair being coarse. The complexion was sallow and pale, with a dusky tinge on the forehead and temples. There was convergent strabismus, and nystagmus was frequently observed. The extremities were habitually cold and bluish. The face had a racant expression. The child took little rotice of anything. She cried almost constantly, and could not stand, sit, or crawl, or speak a single word. The mother said that she herself and her husband were healthy, and that she had a younger child four months old, who also was healthy. The patient was suckled for thirteen months. She had had bronchitis often, but no diarrhoea or convulsions. Her present condition had developed gradually. The tongue was always large. The nystagmus was seen first at the age of sixteen months. The subcutaneous swellings had developed more recently. Figures 1 and 2 , taken from photographs of the child, show very well the characteristic expression of the face and the irregular "Iumpiness" of the back, neck, and limbs. In Marcb, 1892, the child was shown at the Leeds and West Riding Medico-Chirurgical Society as a typical case of sporadic cretinism. I had the patient under observation for 